\title{
Bronchiectasis in Germany: a population- based estimation of disease prevalence
}

\author{
To the Editor:
}

Bronchiectasis is a chronic and progressive disease, which frequently is associated with a significant symptom burden and which may require intensive treatment. To date, epidemiological data on the prevalence of bronchiectasis in Europe are exceedingly scarce due to a great lack of research [1]. However, these data on disease burden are important in order to inform authorities and to allocate resources in healthcare [2], in particular as bronchiectasis is associated with high healthcare system usage as well as significant morbidity and mortality $[3,4]$. The aim of the present study was to estimate the overall prevalence of bronchiectasis in Germany over a 1-year period from a representative sample of routine statutory health insurance claim data, with special attention paid to the distribution of age and sex, and the site of healthcare provision, as well as chronic obstructive pulmonary disease (COPD) as a concomitant condition.

In 2013, Germany had a population of 80.8 million. Among these, 69.9 million subjects (87\%) were covered by the German statutory health insurance. Of those, 11.6 million subjects were covered by a company health insurance fund (figure 1a) [5]. Anonymous health claims data from a subset of this cohort were obtained from the German statutory health insurance. In order to establish representativeness of data, adjustments for age and sex were performed according to the distribution within the German population [5]. In a second step, validation of health risks associated with morbidity was performed according to annually published morbidity prevalence data as provided by the Federal Insurance Authority, which is responsible for the implementation of a risk structure compensation scheme $[6,7]$. Finally, a representative 5\% sample of the general German population consisting of 3895272 individuals was randomly obtained for the year 2013. Data were extracted from this sample using ICD-10 diagnosis code J47 (acquired bronchiectasis) and analysed according to age, sex, the site of healthcare provision (outpatient or hospital care) and the associated condition of COPD, represented as concomitantly recorded ICD-10 diagnosis code J44. Subjects with concomitant cystic fibrosis (ICD-10 diagnosis code E84) were excluded from analysis. Rates and 95\% confidence intervals were calculated using OpenEpi, version 3.03a [8]. Official census data for 2013 was obtained from the German Federal Statistical Office [5]. Because this study is based on anonymous routine data, institutional review board approval and patient consent was not required.

Overall, 2618 subjects with bronchiectasis as any diagnosis and 2595 subjects with bronchiectasis as any diagnosis without concomitant cystic fibrosis (ICD-10 diagnosis code E84) were identified (figure 1a). These individuals included 1347 females (52\%), mean \pm SD age was $65 \pm 14$ years for both males and females. Regarding the site of healthcare provision, 2380 subjects (92\%) were managed in outpatient care, 389 (15\%) were hospitalised and 174 (7\%) received both outpatient and hospital care at least once in 2013. Remarkably, 1493 of 2595 subjects (58\%) with bronchiectasis had the concomitant diagnosis of COPD (ICD-10 code J44; figure 1a). The projected total number of subjects with bronchiectasis was 53807, while the corresponding overall prevalence rate was 67 (95\% CI 64-69) per 100000 population in Germany in 2013. This rate was slightly higher among females compared to males (68 (95\% CI 65-72) versus 65 ( $95 \%$ CI 61-69) per 100000 population). However, due to overlapping 95\% confidence intervals this difference was not statistically significant. The highest prevalence rate of 228 (95\% CI 204-255) per 100000 population was observed among men aged 75-84 years (figure $1 \mathrm{~b}$ ).

The present population-based study provides an estimation of bronchiectasis prevalence of 67 cases per 100000 population in Germany, with the highest rate among those aged $\geqslant 75$ years. So far, as in most other European countries, this important information has been lacking [1]. While we recently provided evidence for a steadily increasing burden of bronchiectasis-associated hospitalisations in Germany between 2005 and 2011 [2], only two studies from the USA analysed healthcare claims based on ICD diagnosis codes in order to estimate the burden of bronchiectasis [9, 10]. WeYcKer et al. [9] analysed 5.6 million adults between 1999 and 2001 and found comparable disease prevalence rates, with an overall disease prevalence of 52 cases of bronchiectasis per 100000 population and the highest rate of 272 per 100000 among those aged $\geqslant 75$ years. SeITz et al. [10] analysed a 5\% sample of the Medicare outpatient claims database of $>2$ million individuals among beneficiaries aged $\geqslant 65$ years from 2000 to 2007. In contrast to our finding of an overall bronchiectasis prevalence of 192 cases per 100000 population among those aged 


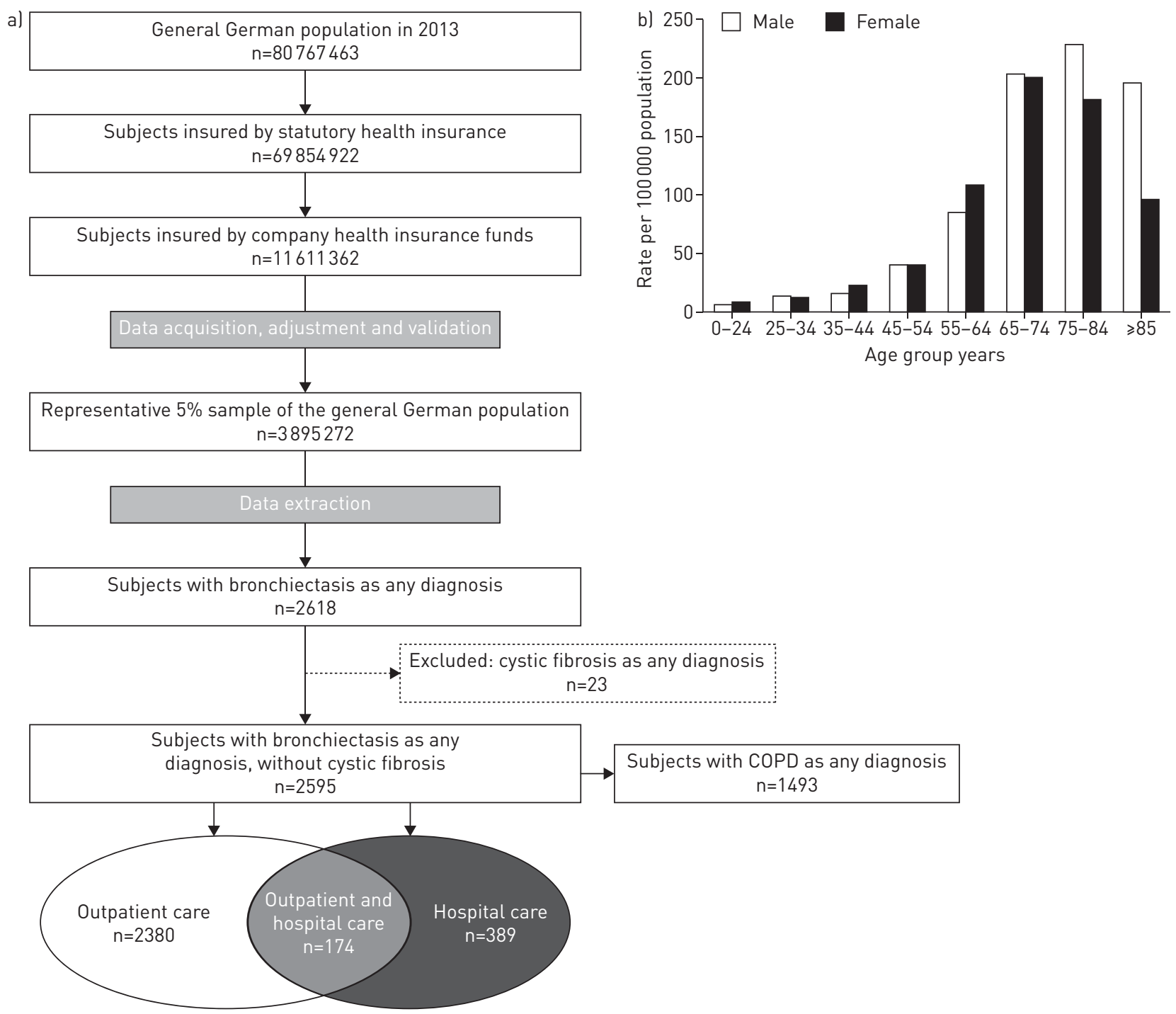

FIGURE 1 a) Data flow diagram and b) prevalence rates of bronchiectasis as any diagnosis by age group and sex, Germany, 2013. COPD: chronic obstructive pulmonary disease.

$\geqslant 65$ years, they found an average annual prevalence in the outpatient setting of 370 cases per 100000 person-years, with the highest prevalence rate of 537 per 100000 among females aged 80-84 years [10]. Of note, in our study on bronchiectasis-associated hospitalisations in Germany we found COPD to be the most important condition in up to $39 \%$ of bronchiectasis-associated hospitalisations [2].

Our findings have several implications. First, our analysis demonstrates that bronchiectasis is not a rare disease in Germany, with a prevalence rate that is well above the cut-off of 5 per 10000 population for the definition of an orphan disease in Europe [11]. Secondly, beyond any doubt, our findings confirm that the major burden of bronchiectasis in Germany is managed in outpatient care [2, 10]. Moreover, although bronchiectasis is commonly regarded as a chronic condition that may benefit from specialised care and regular follow-up, obviously the majority of patients hospitalised with bronchiectasis were not followed as such in outpatient care $(215 / 389 ; 55 \%)$ (figure $1 \mathrm{a}$ ). This finding may point towards unmet medical needs concerning the transition from hospital to outpatient care. Last, the majority of patients with bronchiectasis presented with chronic airway obstruction $(1493 / 2595 ; 58 \%)$ as indicated by COPD as a concomitant diagnosis. This finding is stirring up scientific debate about the delineation of COPD with associated bronchiectasis from bronchiectasis with obstructive lung function $[12,13]$. From our point of view, our data rather supports the notion that the majority of subjects with bronchiectasis have obstructive lung function than it provides evidence for the association with COPD in the narrower sense. Keeping in mind that still no approved pharmacological treatment options exist and that off-label use carries a significant risk of refund claims from health insurance companies for prescribing physicians in Germany [4], it becomes clear that the 
diagnosis of COPD (ICD-10 code J44) will probaby be recorded if there is evidence of chronic airflow obstruction in a bronchiectasis patient who is prescribed bronchodilators and/or inhaled corticosteroids.

The present study has strengths and inherent limitations. Depending on ICD-10 diagnosis codes, our study is most likely still underestimating the true prevalence of bronchiectasis in Germany. ICD codes are primarily used for reimbursement purposes. They are considered to have high specificity, but only moderate sensitivity, to be subject to potential sources of errors, and to lack validation for bronchiectasis [14], and do not allow identification of the underlying condition. However, to our best knowledge, this is the first population-based analysis of bronchiectasis prevalence based on routine statutory health insurance claims, including a representative 5\% sample of a general population in Europe.

In conclusion, our study provides robust evidence that bronchiectasis is not an orphan disease in Germany, with the majority of subjects being managed in the outpatient setting and presenting with chronic airway obstruction. National and international collaborations like the German and the European bronchiectasis registries PROGNOSIS and EMBARC will provide valuable additional data on the epidemiology of bronchiectasis, in particular with respect to the association between bronchiectasis and COPD [13, 15].

(-1) @ERSpublications

Robust evidence for the prevalence of bronchiectasis in Germany and its association with chronic airflow obstruction http://ow.ly/QvSBo

Felix C. Ringshausen ${ }^{1,2}$, Andrés de Roux ${ }^{3}$, Roland Diel ${ }^{2,4}$, David Hohmann ${ }^{5}$, Tobias Welte ${ }^{1,2}$ and Jessica Rademacher ${ }^{1}$

${ }^{1}$ Dept of Respiratory Medicine, Hannover Medical School, Hannover, Germany. ${ }^{2}$ Member of the German Center for Lung Research (DZL). ${ }^{3}$ Pneumologische Praxis am Schloss Charlottenburg, Berlin, Germany. ${ }^{4}$ Institute for Epidemiology, University Medical Center Schleswig-Holstein, Kiel, Germany. ${ }^{5}$ HGC Gesundheitsconsult, Düsseldorf, Germany.

Correspondence: Felix C. Ringshausen, Dept of Respiratory Medicine, Hannover Medical School, Carl-Neuberg-Strasse 1, 30625 Hannover, Germany. E-mail: Ringshausen.Felix@mh-hannover.de

Received: June 172015 | Accepted after revision: June 192015 | First published online: Aug 202015

Support statement: Data adjustment and analysis were kindly supported by Grifols Germany, Frankfurt, Germany.

Conflict of interest: Disclosures can be found alongside the online version of this article at www.erj.ersjournals.com

Acknowledgement: Data adjustment and analysis were performed by the Health Risk Institute in coordination with Elsevier Health Analytics (both Berlin, Germany).

\section{References}

1 Bronchiectasis. In: Gibson J, Loddenkemper R, Sibille Y, et al., eds. The European Lung White Book: Respiratory Health and Disease in Europe. Sheffield, European Respiratory Society, 2013; pp. 176-183.

2 Ringshausen FC, de Roux A, Pletz MW, et al. Bronchiectasis-associated hospitalizations in Germany, 2005-2011: a population-based study of disease burden and trends. PLoS One 2013; 8: e71109.

3 Chalmers JD, Goeminne P, Aliberti S, et al. The bronchiectasis severity index. An international derivation and validation study. Am J Respir Crit Care Med 2014; 189: 576-585.

4 Chalmers JD, Aliberti S, Blasi F. Management of bronchiectasis in adults. Eur Respir J 2015; 45: 1446-1462.

5 German Federal Statistical Office. Facts \& Figures - State \& Society - Federal Statistical Office (Destatis). 2015. https:/http://www.destatis.de/EN/FactsFigures/SocietyState/SocietyState.html Date last accessed: June 5, 2015.

6 Nuscheler R, Knaus T. Risk selection in the German public health insurance system. Health Econ 2005; 14: 1253-1271.

7 Buchner F, Goepffarth D, Wasem J. The new risk adjustment formula in Germany: implementation and first experiences. Health Policy 2013; 109: 253-262.

8 Dean AG, Sullivan KM, Soe MM, et al. OpenEpi: Open Source Epidemiologic Statistics for Public Health, Version 3.03a. http://www.OpenEpi.com. Date last updated: May 4, 2015. Date last accessed: June 5, 2015.

9 Weycker D, Edelsberg J, Oster G, et al. Prevalence and economic burden of bronchiectasis. Clin Pulm Med 2005; 12: 205-209.

10 Seitz AE, Olivier KN, Adjemian J, et al. Trends in bronchiectasis among Medicare beneficiaries in the United States, 2000-2007. Chest 2012; 142: 432-439.

11 European Commission. Policy - European Commission. http://ec.europa.eu/health/rare_diseases/policy/index_en. htm Date last updated: June 5, 2015. Date last accessed: June 6, 2015.

12 Hurst JR, Elborn JS, Soyza AD. COPD-bronchiectasis overlap syndrome. Eur Respir J 2015; 45: 310-313.

13 Blasi F, Chalmers JD, Aliberti S. COPD and bronchiectasis: phenotype, endotype or co-morbidity? COPD 2014; 11: 603-604.

14 O’Malley KJ, Cook KF, Price MD, et al. Measuring diagnoses: ICD code accuracy. Health Serv Res 2005; 40: $1620-1639$.

15 Rademacher J, de Roux A, Ringshausen FC. PROGNOSIS - das deutsche Bronchiektasen-Register [PROGNOSIS the German bronchiectasis patient registry]. Pneumologie 2015; 69: 391-393. 